\title{
"I want your kidney!" Information seeking, sharing, and disclosure when soliciting a kidney donor online
}

\author{
Kaitlin Light Costello \\ School of Information and Library Science \\ University of North Carolina at Chapel Hill \\ Chapel Hill, NC, USA \\ Angela P. Murillo \\ School of Information and Library Science \\ University of North Carolina at Chapel Hill \\ Chapel Hill, NC, USA \\ Corresponding author at: \\ Kaitlin Light Costello \\ School of Information and Library Science \\ University of North Carolina at Chapel Hill \\ 216 Lenoir Drive, CB \#3360 \\ 100 Manning Hall \\ Chapel Hill, NC 27599-3360 \\ USA
}

Tel: 919-962-8366

Fax: 919-962-8071

Email: kaitcost@email.unc.edu

Role of funding: This study was partially supported by funding from the National Institute for Nursing Research Interventions for Preventing and Managing Chronic Illness (5T32NR007091; PI: M. Mishel, PhD).

Acknowledgements: The authors wish to thank Dr. Barbara Wildemuth for her helpful input throughout the study.

\section{This is an author post-print.}

This article was published in Patient Education and Counseling in March 2014, doi:10.1016/i.pec.2013.11.009. 


\section{Abstract}

\section{Objective}

This study investigates how people use the Internet to search for an altruistic kidney donor. Although many opinion pieces on this phenomenon have been written, this is the first qualitative study focused on online kidney solicitation from the potential recipient's point of view.

\section{Methods}

Eight participants - four who successfully found donors and four who were still searching - were interviewed, and inductive content analysis was performed.

\section{Results}

Three themes appear in our data: choosing to go online to find a donor, information hubs, and information flow. These themes emphasize the process of information seeking and disclosure when using the Internet to find an altruistic kidney donor.

\section{Conclusion}

The benefits from searching online are not limited to the possibility of finding a kidney donor. Our participants also experience a wide variety of socially supportive activities from their online networks. Additionally, our participants felt that the potential benefits of finding a donor online outweighed risks to their privacy.

\section{Practice implications}

Not all potential recipients will find a kidney donor online. Participants indicated that through sharing educational information, staying positive, and actively maintaining their online solicitation efforts they received numerous social benefits even if they did not find a kidney donor.

\section{Introduction}

On November 1, 2013, there were 98,597 candidates in the United States waiting for a kidney transplant, according to the U.S. Organ Procurement and Transplantation Network (OPTN). In 2011, 5,139 people died while waiting for a kidney, greatly surpassing the mortality rate for all other organs. The median waiting time for a deceased donor is 3 years across all blood types. Living donations are possible and commonly come from family or friends. The waiting list continues to grow, and efforts to increase the number of donors are ongoing (1). The responsibility to find a living donor is the job of the recipient, and many turn to people in their social networks in order to find potential donors $(2,3)$.

Increasingly, individuals create, manage, and define their social networks online (4). As part of this trend, individuals with end-stage renal disease (ESRD) have begun to turn to the Internet in search of a living kidney donor. In this search, they may discuss their need on YouTube, Facebook, Twitter, Craigslist, personal blogs, and 
kidney matching sites (e.g. 5,6). The number of kidney donors solicited online is growing, and this trend is expected to continue (7).

Opinion pieces about this topic have been written recently by transplant surgeons, medical ethicists, and nephrologists; nearly all of these articles explain the pressing need for research in this area (7-11). However, to our knowledge only one study has been conducted that investigates online kidney solicitation (12). This prior study looked specifically at organ matching sites, not at activity within one's existing social networks. Our study furthers an understanding of how and why ESRD patients and their caregivers use the Internet to find a kidney donor through focusing on the information seeking and sharing aspects of the process.

\section{Methods}

As is common in exploratory research, the researchers chose several areas of the phenomenon to explore rather than identifying a central research question, including:

- The decision to go online to find a kidney donor.

- Information seeking, sharing, and management processes undertaken by potential recipients and/or caregivers online.

- The tension between disclosing personal health information online and maintaining privacy.

After obtaining approval from our Institutional Review Board (IRB \#12-0821), we began by searching Google and Facebook for people currently looking for a kidney donor online and people who had successfully found a kidney donor online. The following search terms were used: "need a kidney," "looking for kidney donor," "kidney donor wanted," "found a kidney online," "donated kidney to stranger," and "found donor on Internet". These terms were selected because they either correspond with commonly-used titles of Facebook groups for people searching for kidneys or because they are often found in news articles about recipients who successfully found donors online.

Potential participants were contacted privately via email or Facebook messages. English-speaking patients and caregivers managing the solicitation process over the age of 18 were eligible. Participants who successfully located a donor online must have posted their initial solicitation on Facebook, Twitter, Craigslist, or YouTube between the dates of April 1, 2002 and April 1, 2012. The date range was wide to ensure that enough participants would be eligible, since this practice is fairly new. Participants that were still looking for a donor online must have posted their initial solicitation on one of the above sites between April 1, 2010 and April 1, 2012. A shorter date range was selected in order to ensure that participants were still actively searching for a donor online. Participants were offered a VISA gift card as a token of appreciation for their time. The researcher was able to recruit eight total 
participants - four in each category - a sufficient sample size for an exploratory study (13).

Between June and October of 2012, participants were interviewed over the telephone for approximately one hour about their experiences soliciting a kidney donor online. The interviews were semi-structured and included questions such as "Tell me a bit about why you decided to go online to find a kidney donor" and "What kind of health information did you decide to share online?" These interviews were recorded and transcribed. Pseudonyms were assigned to each participant.

Inductive content analysis was chosen to analyze the interview data. In this method, the researchers develop codes and categories from the data rather than applying an existing framework (14). It allows for flexibility in the design of research, which means that it emphasizes meaning, consequences, and context, making it ideally suited for questions about a phenomenon or process $(15,16)$.

Codes were developed with a focus on themes related to information seeking, information sharing, and disclosure from each interview. The resulting codes were collapsed into three main categories throughout the process, and descriptions of each code and category were made. Both authors coded all of the interviews; in order to assess reliability, Cohen's kappa coefficients were calculated for each category.

\section{Results}

Three main categories were developed: choosing to go online to find a donor, information hubs, and information flow. To assess inter-coder reliability, Cohen's kappa $(\kappa)$ was calculated on two interviews coded by each researcher. The formula was weighted according to source size. The average $\kappa$ coefficient for all of the codes was .8798, indicating substantial agreement - particularly for exploratory research. The weighted $\kappa$ coefficients for each category were also substantial (see Table 1).

\subsection{Choosing to go online to find a donor}

Participants had often not found a match in their face-to-face networks, so they turned to the Internet to widen their search. Most participants decided to go online after hearing success stories from others in traditional media outlets or through friends: "Seeing someone else do this on Facebook kind of inspired me and gave me some strategies and ideas on how to proceed," said Ryan.

Participants felt that creating and maintaining an online presence was low-stress and low-cost, especially when compared with asking people face-to-face. "Saying 'Can I have your kidney?' - those are really hard words to say," explained Ted. Darren agreed: "The Internet is a very good way to reach a lot of people and there is no expense. It's easy to do. It was hard to go up to somebody and say, 'Hey, would you consider, maybe, seeing if we're a match?' It wasn't hard at all to send out a message on the Internet, because I wasn't staring somebody right in the face and asking them this incredible imposition - to have surgery on my behalf." Julio 
thought that potential donors appreciated having the process mediated by the Internet: "Being able to get information online and not actually have to talk to me directly about it... has been helpful. I think if I didn't put that information online, that perhaps a number of people that are getting tested... well, that would be a much smaller number."

While healthcare providers encouraged participants to find a living donor, they did not recommend that patients use the Internet in their search. As Harriet explained, "They all encourage you to go find living donors, and they always say, go to your family. They don't ever encourage you to go online and look." In fact, some participants said that their healthcare providers actively discouraged it, as Philip explains: "A number of the healthcare providers were hesitant to recommend using the Internet because of all the pitfalls that can come from putting the word out, for fear that we would be susceptible to maybe somebody preying on people like us." All of the participants were offered a kidney in exchange for payment; the common response to these queries was to block the offending party. "I have no interest in participating in purchasing a kidney from someone. The easiest thing for me to do is to just shut that conversation down," explained Ryan.

After going online with their need, participants were met with an outpouring of support, ranging from simple messages of solidarity to offers to get tested as a potential donor. "My online presence," says Ryan, "has served tremendously in really building an overwhelming sense of support." Participants also described the large volume of potential donors contacting their transplant center: "We flooded the hospital's call center," said Ted. Even when the solicitation did not cause a magnitude of donor responses, as has occurred in Julio's case, "there's this immense amount of emotional support and affirmation, on a daily basis."

\subsection{Information hubs}

Julio explained the process of creating an information hub online: "I decided to run this like a campaign. I created a brand, a website - I created information hubs. I needed to have some sort of hub that was always available to get people information, even when I was unavailable to get it to them," he explained. The hub allowed him and other participants to take days off due to fatigue.

Participants all chose one hub where the majority of their solicitation activities occurred. Facebook was the preferred channel: participants were already connected to an extended network of acquaintances through the service and it was part of their usual online routine. Facebook also made it simple for friends to share posts, broadcasting messages to a larger audience: "We had a lot of good friends who were persistent in sharing every single thing I posted, and demanding that their friends also share it," explained Bonnie.

Many participants asked their friends to share their page with others: "I said, 'Even if you're not interested in being tested, please do me a favor and forward the page.' So I got this exponential effect people forwarding to people forwarding to people, and it just keeps spreading to a wider and wider network," said Darren. Participants found that traffic to their pages increased when other people acted as their 
advocates. As Ryan explained, "If you can get someone else to advocate for you and say, 'Hey, look at this guy's Facebook page,' then people don't see it as self-serving. I get way more traffic on my page than if I say, 'Hey, I'm Ryan, I have kidney disease, can you check my page out?'”

Marketing one's self was a key part of the search process. Bonnie explained staying positive online: "If I took pictures of [my husband] at dialysis with a thumbs up... that would get shared more than other things. I tried to keep it lighter and upbeat and more positive, because I thought people would share that stuff more." Ted refrained from posting embarrassing or concerning information about his health: "There is this slew of indignities that illness brings, and I wasn't about to tweet about them." However, it was important for participants to be realistic about their situation: "I don't want to overplay the victim, but I think it helps to build a brand of an injured person that does need help," said Ted.

Individuals also used their hubs to share general educational information about kidney disease. For example, Bonnie shared news about kidney disease because she wanted to drive traffic to her page: "I would pay attention to what kind of posts got more people to share. I tried to put information about what goes on when you donate a kidney, what the process is.... I wanted to keep people interested and educated."

\subsection{Information flow}

Because healthcare providers are not allowed to give potential recipients information about potential donors due to privacy concerns, participants had to get this information from the potential donors themselves. Often, the participants did not want to ask potential donors about the process directly and instead waited for the potential donors to contact them.

Some participants chose to manage information flow as much as possible in order to maintain control. Philip explained: "Any requests for information about donating were filtered through me, and I sent them back the application from the hospital. Then it was their responsibility to submit it to the hospital." Others simply provided contact information for the transplant center online.

In some cases, potential donors purposefully hid information from participants. For example, Darren's donor knew that she was a match, but she wanted to make sure he had a healthy lifestyle before donating. She confirmed this by asking him questions about his health via Facebook messages. In contrast, both Bonnie and Ted were updated throughout the testing process by their eventual donors. Participants generally allowed potential donors to maintain control over both the amount and type of contact, which Bonnie describes: "She emailed me first and told me she was going to be tested. Then she asked if she could text us about stuff. And then when she got the results back, she asked if she could call us." Multiple participants described this progression from less intimate to more intimate forms of communication with their eventual donors, a finding that should be explored in future research. 


\section{Discussion and conclusion}

\subsection{Discussion}

There were two major findings from this study: the value that participants got from searching for a donor online, and the tensions they experienced between privacy and disclosure of personal health information.

\subsubsection{The value of looking for a donor online}

Participants were met with what they called an overwhelming outpouring of support that began immediately and continued throughout the process - even after they found their donor. In fact, some participants got even more support after the transplant due to media involvement. Social support is vital during illness, particularly in cases where patients feel isolated by their condition - common for people with ESRD (17). Most of the support offered to our participants was emotional - expressions of solidarity, prayers, and notes of encouragement - and tangible, in the form of money for medical bills or offers to be tested as a donor. Informational support was present, but less common.

Social support can be either perceived, which is the feeling that one has a support network, or enacted, which is a direct manifestation of support from others (18). Both types of support were present in our study. Enacted support was seen when people sent our participant messages of solidarity and notifications that they were undergoing the testing process. When others shared our participants' messages with their own networks, this was an expression of enacted support that increased perceived support because the network of people who might become tested grew. Posting frequently was a common strategy used to garner support, and was also a motivation for posting general educational content. The few participants that did not post frequently had low perceptions of the support available online, suggesting that active maintenance is an important component of finding value in the process.

\subsubsection{Choices about privacy and disclosure}

Our data indicates that participants underwent a cost/benefit analysis when deciding whether to search for a donor online and determined that the potential risk of disclosing health information online was worth the possible reward of finding a donor. This type of analysis is common in situations where people are balancing the risks and rewards of disclosure (19). One common risk is concern over negative reactions, such as rejection or embarrassment. However, disclosing online reduces these risks, a finding corroborated in other studies of online disclosure (20). Disclosing on Facebook also normalizes the process - since participants who used Facebook to solicit were regular Facebook users, they were already conditioned to disclose there. The Internet also mediated the difficult process of asking someone to consider becoming a kidney donor, which is often a challenging conversation $(2,3)$ by prolonging the time-span of communication and eliminates many social cues typical in face-to-face interactions, mitigating many of these difficulties (21).

Participants discussed the importance of keeping their posts positive, indicating mindfulness about disclosure. Staying positive helped manage impressions and 
possibly aided participants in coping with their illness. For many of our participants, disclosure of personal information was not an issue, because caregivers were managing the online presence of the ESRD patient. In these cases, the patients themselves did not have control over what information was shared (22). Although it is possible that this caused tension between the caregivers and patients (e.g. 23), we did not examine this specifically.

\subsection{Conclusion}

To our knowledge, this is the first qualitative study on online organ solicitation focused on recipients. We conducted eight semi-structured interviews with patients and caregivers who had either successfully found a donor online or were still looking. We analyzed these interviews using inductive content analysis and developed codes relevant to the phenomena of interest.

While our participants did not go online specifically to look for social support, they were met with a barrage of support throughout and beyond the seeking process. Our findings indicate that all types of social support - emotional, informational, and tangible - are present online, which extends prior research on social support for health on the Internet (e.g. 24).

Although some of the participants were concerned about their own privacy when they shared their need online, the potential benefits of finding a donor greatly outweighed perceived risks to their personal privacy. However, we did not talk to any individuals who had made the conscious choice to refrain from looking for a donor online. Future work with a broader sample is necessary in order to build a better understanding of the cost/benefit analyses and tradeoffs associated with the process.

\subsection{Practice implications}

Participants discussed several strategies that can be translated into practice. Healthcare providers may want to emphasize these strategies if patients express interest in using the Internet to find a kidney donor. Providers should also stress that these techniques will not guarantee that a patient will find a kidney donor online; they are merely recommendations that are likely to increase the amount of social support received.

- Sharing educational information about kidney disease instead of focusing on the recipient's immediate need.

- Actively maintaining the page with frequent posts and updates in order to keep followers involved and primed to share updates with others.

- Posting positive messages.

- Folding the solicitation activity into one's usual activities and drawing on existing online social networks.

- Telling a compelling, interesting story in order to increase interest. 


\section{References}

1. Organ Procurement and Transplantation Network. OPTN/SRTR 2011 annual data report: Kidney [Internet]. Rockville, MD: Department of Health and Human Services, Health Resources and Services Administration, Healthcare Systems Bureau, Division of Transplantation; 2011. Available from: http://srtr.transplant.hrsa.gov/annual_reports/2011/pdf/01_kidney_12.pdf

2. Afifi WA, Morgan SE, Stephenson MT, Morse C, Harrison T, Reichert T, et al. Examining the decision to talk with family about organ donation: Applying the theory of motivated information management. Commun Monogr. 2006;73(2):188-215.

3. Morgan SE, Harrison TR, Long SD, Afifi WA, Stephenson MS, Reichert T. Family discussions about organ donation: how the media influences opinions about donation decisions. Clin Transplant. 2005;19(5):674-82.

4. Duggan M, Brenner J. The Demographics of Social Media Users - 2012 [Internet]. 2013 Feb. Available from: http://www.pewinternet.org/Reports/2013/Social-media-users.aspx

5. Block M. Mayor Donates Kidney To Facebook Friend : NPR [Internet]. Things Consid. 2010 [cited 2011 Aug 15]. Available from: http://www.npr.org/templates/story/story.php?storyId=126199103

6. Flood J. The Flood Sisters Kidney Foundation of America: Our Story [Internet]. 2009 [cited 2011 Aug 15]. Available from:

http://www.floodsisters.org/index.php?link=20 (Archived by WebCite ${ }^{\circledR}$ at http://www.webcitation.org/60wqDxwnp)

7. Williams ME. Internet organ solicitation, explained. Adv Chronic Kidney Dis. 2006;13(1):70-5.

8. Brennan P. Public Solicitation of Organs on the Internet: Ethical and Policy Issues. J Emerg Nurs. 2006 Apr;32(2):191-3.

9. Rodrigue JR, Cornell DL, Kaplan B, Howard RJ. Patients' willingness to talk to others about living kidney donation. Prog Transplant Aliso Viejo Calif. 2008 Mar;18(1):25-31.

10. Wright L, Campbell M. Soliciting Kidneys on Web Sites: Is it Fair? Semin Dial. 2006 Jan 1;19(1):5-7.

11. Wright L. Ethical controversies in public solicitations for organs. Transplant Rev. 2008 Jul;22(3):184-6. 
12. Neidich EM, Neidich AB, Cooper JT, Bramstedt KA. The Ethical Complexities of Online Organ Solicitation via Donor-Patient Websites: Avoiding the "Beauty Contest."Am J Transplant. 2011 Sep 22;12(1):43-7.

13. Guest G, Bunce A, Johnson L. How Many Interviews Are Enough? An Experiment with Data Saturation and Variability. Field Methods. 2006 Feb 1;18(1):59-82.

14. Hsieh H-F, Shannon SE. Three Approaches to Qualitative Content Analysis. Qual Health Res. 2005 Nov 1;15(9):1277-88.

15. Elo $\mathrm{S}$, Kyngäs $\mathrm{H}$. The qualitative content analysis process. J Adv Nurs. 2008;62(1):107-15.

16. Zhang Y, Wildemuth BM. Qualitative analysis of content. Applications of social science research methods to questions in information and library science. Westport, CT: Libraries Unlimited; 2009. p. 308-19.

17. Kierans C. Narrating Kidney Disease: The Significance Of Sensation And Time In The Emplotment Of Patient Experience. Cult Med Psychiatry. 2005;29(3):34159.

18. Sarason BR, Sarason IG, Pierce GR. Traditional views of social support and their impact on assessment. Social support: An interactional view. New York, NY: John Wiley \& Sons; 1990. p. 9-25.

19. Petronio SS. Boundaries of privacy: dialectics of disclosure. Albany, NY: SUNY Press; 2002.

20. Nguyen M, Bin YS, Campbell A. Comparing Online and Offline Self-Disclosure: A Systematic Review. Cyberpsychology Behav Soc Netw. 2012 Feb;15(2):103-11.

21. Tidwell LC, Walther JB. Computer-Mediated Communication Effects on Disclosure, Impressions, and Interpersonal Evaluations: Getting to Know One Another a Bit at a Time. Hum Commun Res. 2002 Jul;28(3):317-48.

22. Costello KL. Information ethics: Searching for a kidney donor online. Proceedings of the 76th ASIS\&T Annual Meeting [Internet]. Montreal, Cananda: Association for Information Science and Technology; 2013. Available from: http://k8lin.com/selfarchived/Costello_Ethics_ASIST_08-nov-13.pdf

23. Veinot TC, Kim Y-M, Meadowbrooke CC. Health information behavior in families: supportive or irritating? Proc Am Soc Inf Sci Technol. 2011;48(1):110.

24. Chuang KY, Yang CC. Helping you to help me: exploring supportive interaction in online health community. Proceedings of the 73rd ASIS\&T Annual Meeting 
on Navigating Streams in an Information Ecosystem - Volume 47 [Internet]. Pittsburgh, Pennsylvania: American Society for Information Science; 2010 [cited 2011 Aug 15]. p. 9:1-9:10. Available from:

http://portal.acm.org.libproxy.lib.unc.edu/citation.cfm?id=1920331.1920344 